\title{
INFLUÊNCIA DE DIFERENTES NÍVEIS DE FDN DIETÉTICO NO CONSUMO E DIGESTIBILIDADE APARENTE DE OVELHAS SANTA INẾ ${ }^{1}$
}

\author{
Influence of different levels of dietetic ndf on the intake and \\ apparent digestibility of Santa Inês ewes
}

\author{
Gilberto de Lima Macedo Junior², Juan Ramòn Olalquiaga Pérez ${ }^{3}$, Thaís Romano de Vasconcelos e Almeida ${ }^{4}$, \\ Oiti José de Paula ${ }^{5}$, Patrícia Maria de França ${ }^{6}$, Roberta de Moura Assis ${ }^{7}$
}

\begin{abstract}
RESUMO
Objetivou-se com o presente trabalho avaliar a influência de diferentes níveis de fibra em detergente neutro dietético sobre o consumo e digestibilidade aparente de ovelhas Santa Inês. Para isto foi realizado um ensaio de digestibilidade in vivo, no Setor de Ovinocultura, do Departamento de Zootecnia da Universidade Federal de Lavras. Foram utilizadas 16 ovelhas adultas, não gestantes e não lactantes, da raça Santa Inês, com peso vivo de $45,01 \pm 2,15 \mathrm{~kg}$, distribuídas em delineamento quadrado latino (4x4), com quatro tratamentos $(8,67 \% ; 17,34 \% ; 26,01 \%$ e $34,69 \%$ de FDN forrageiro). Os tratamentos influenciaram as variáveis referentes ao consumo de MS, MO, ED, EM, PB, PD, FDN e FDA, bem como os coeficientes de digestibilidade aparente da MS, MO e FDA. Já os coeficientes de digestibilidade de FDN e PB não sofreram influência dos tratamentos.
\end{abstract}

Termos para indexação: Carboidratos, fibra em detergente neutro, ingestão, ovinos.

\begin{abstract}
This research was carried out at the Sector of Ovinocultura of the Animal Science Department - UFLA in order to investigate the effect of different levels of Neutral Detergent Fiber ( NDF) in the diet fed ovine on nutrients intake and apparent digestibility of the diet and on the feeding behavior. A feeding behavior study and an in vivo digestibility assay were conducted to determine the nutrients intake and the apparent digestibility coefficient. Sixteen adults, not pregnant and not lactating, Santa Inês ewes weighting $45,01 \pm 2,15 \mathrm{~kg}$ were used. The experimental design was in a $4 \mathrm{x} 4$ latin square, with four treatments $(8,67 \% ; 17,34 \% ; 26,01 \%$ and $34,69 \%$ of forage NDF) and four periods. The intake of DM, OM, metabolizable energy, CP, digestible protein, NDF, digestible NDF, $\mathrm{ADF}$ and digestible $\mathrm{ADF}$ as well as the apparent digestibility of DM, OM and ADF were influenced by treatments tested. Therefore the apparent digestibility of NDF and CP, were not influenced by treatments.
\end{abstract}

Index terms: Carbohidrates, neutral detergent fiber, intake, ovine.

(Recebido para publicação em 15 de junho de 2004 e aprovado em 7 de junho de 2005)

\section{INTRODUÇÃO}

A fibra vem sendo utilizada para caracterizar os alimentos (SOEST, 1994) e para estabelecer limites de inclusão de ingredientes nas rações (MERTENS, 1992), entretanto, não existe consenso a respeito da definição de fibra, assim como a respeito da concentração de fibra na dieta que otimiza o consumo de energia. A fibra em detergente neutro (FDN) é uma medida do conteúdo total de fibra insolúvel do alimento e constitui o parâmetro mais usado para o balanceamento de dietas uma vez que interfere na qualidade da mesma e não são poucos os estudos que relacionam a quantidade de FDN nos alimentos e o respectivo consumo deste em ruminantes. A presença da fibra, em maiores ou menores proporções, afeta três características dos alimentos importantes na nutrição animal: está relacionada com a digestibilidade e com o valor energético, com a fermentação ruminal e pode estar envolvida no controle da ingestão de alimento (MERTENS, 1992).

Alguns estudos vêm mostrando alta correlação entre consumo da matéria seca e o nível de FDN da dieta. Nesse sentido, Rode et al. (1985) verificaram que o aumento do nível de concentrado e a redução do nível de FDN levaram a um aumento na digestibilidade aparente da matéria seca e matéria orgânica. Contudo, Grant \& Mertens (1992) afirmaram que uma redução na digestão da fibra pode ocorrer com o aumento da quantidade de concentrado e redução na quantidade de volumoso e fibra na dieta, em decorrência do aumento nas proporções de carboidratos prontamente fermentáveis.

O consumo e a digestibilidade são parâmetros chaves em vários sistemas de formulação de dietas para

\footnotetext{
1 Trabalho pertencente à dissertação do primeiro autor.

2 M.Sc., Universidade Federal de Lavras/UFLA Cx. P. 3037 - 37200-000 - Lavras/MG.

${ }^{3}$ Professor do departamento de Zootecnia da Universidade Federal de Lavras/UFLA - Cx. P. 3037 - 37200-000 - Lavras/MG. jperez@ufla.br

${ }^{4}$ Mestranda da Universidade Federal de Lavras/UFLA, bolsista CAPES.

${ }^{5}$ Doutorando da Universidade Federal Lavras/UFLA, bolsista CNPq.

${ }^{6}$ Mestranda da Universidade Federal Lavras/UFLA.

${ }^{7}$ Mestranda da Universidade Federal de Lavras/UFLA, bolsista CAPES.
} 
ruminantes. A medição desses parâmetros faz-se necessária, pois, estes possuem alta correlação com a ingestão de matéria seca e eficiência na absorção e aproveitamento dos nutrientes. De acordo com Santini et al. (1992), os coeficientes de digestibilidade aparente usados na avaliação dos alimentos podem ser influenciados por uma série de fatores, sendo que entre estes, a relação volumoso:concentrado está, com certeza, entre os fatores mais importantes.

Realizou-se este estudo com o objetivo de avaliar a influência de diferentes níveis de FDNf no consumo de matéria seca e digestibilidade aparente dos nutrientes em ovelhas Santa Inês.

\section{MATERIAL E MÉTODOS}

O experimento foi conduzido no Departamento de Zootecnia, da Universidade Federal de Lavras - UFLA. O experimento foi realizado em quatro períodos subseqüentes, de abril a junho de 2003. Em cada um dos períodos os procedimentos foram semelhantes, sendo a diferença entre os períodos a forma com que os animais foram distribuídos nos tratamentos. Os animais foram alojados em gaiolas metabólicas individuais próprias para o ensaio de digestibilidade in vivo, providas de comedouro, bebedouro e cocho próprio para suplementação mineral. Cada gaiola metabólica possuía, acoplado ao assoalho, um sistema de captação total de fezes e urina. As fezes eram recolhidas em bandejas plásticas e a urina ficava acondicionada em baldes plásticos, adaptados com uma tela separadora, evitando que as fezes e a urina se misturassem. Cada balde recebeu $100 \mathrm{~mL}$ de ácido sulfúrico $\left(\mathrm{H}_{2} \mathrm{SO}_{4}\right)$ a $2 \mathrm{~N}$ a fim de evitar fermentação microbiana perdas de nitrogênio. Foram utilizadas 16 ovelhas da raça Santa Inês com peso médio e desvio padrão de $45,01 \pm 2,15 \mathrm{~kg}$, vazias e não lactantes, em 4 tratamentos. $\mathrm{O}$ delineamento experimental utilizado foi o quadrado latino, sendo quatro períodos $4 \times 4$. As variáveis foram analisadas por regressão e por comparação de médias (teste de Tukey) utilizando-se o pacote estatístico SAS INSTITUTE (1992).

A alimentação dos animais foi oferecida em duas refeições diárias, (às 8 horas e às 15 horas), sendo que a primeira refeição continha $60 \%$ do total diário ofertado. As dietas foram balanceadas segundo o ARC (1980), fim de suprir as necessidades dos animais e, permitindo uma sobra de $10 \%$. Na Tabela 1 encontram-se os tratamentos, a composição bromatológica e a proporção de ingredientes.

TABELA 1 - Composição bromatológica e proporção dos ingredientes das dietas.

\begin{tabular}{lcccc}
\hline & Trat A & Trat B & Trat C & Trat D \\
\hline MS \% & \multicolumn{3}{c}{ Composição Bromatológica } \\
FDNf \% & 83,44 & 83,10 & 82,49 & 83,22 \\
FDA \% & 8,67 & 17,34 & 26,01 & 34,69 \\
PB \% & 10,92 & 15,99 & 32,35 & 38,90 \\
Cinzas \% & 19,59 & 20,47 & 20,61 & 21,02 \\
MO \% & 4,41 & 4,49 & 4,60 & 4,70 \\
EM kcal/g & 95,59 & 95,51 & 95,40 & 95,29 \\
& 2.954 & 2.948 & 2.945 & 2.813 \\
\hline Feno & \multicolumn{3}{c}{ Proporção dos Ingredientes (\%) } \\
Milho & 20,00 & 30,00 & 40,00 \\
Farelo de soja & 10,00 & 56,50 & 46,50 & 37,50 \\
Premix & 66,50 & 22,50 & 22,50 & 22,50 \\
\hline
\end{tabular}

Análises realizadas no Laboratório de Pesquisa Animal do Departamento de Zootecnia da Universidade Federal de Lavras (UFLA). Matéria seca (MS), fibra em detergente neutro de origem forrageira (FDNf), fibra m detergente ácido (FDA), proteína bruta (PB), matéria orgânica (MO) e energia metabolizável (EM).

Ciênc. agrotec., Lavras, v. 30, n. 3, p. 547-553, maio/jun., 2006 
Os quatro períodos experimentais foram consecutivos e imediatos e apresentaram, cada um, uma fase pré-experimental e uma fase de coletas. No primeiro período, a fase pré-experimental teve duração de 15 dias, tendo 5 dias a mais que os outros períodos, para que os animais pudessem se adaptar à gaiola metabólica, nas demais fases o período de adaptação foi de 10 dias. A fase de coleta consistia de 5 dias. Era retirada uma amostra do feno e dos diferentes concentrados fornecidos, diariamente, a fim de se obter a composição bromatológica das dietas experimentais. $\mathrm{O}$ alimento recusado (sobra) era coletado individualmente, antes de se oferecer a refeição matutina, sendo pesado e amostrado diariamente. As fezes bem como as urinas foram recolhidas pela manhã. Nessas amostras foram determinadas: matéria seca (MS); fibra em detergente neutro (FDN); fibra em detergente ácido (FDA); proteína bruta (PB); energia bruta (EB) e cinzas (CI). Nas amostras de urina foram feitas as análises de proteína bruta $(\mathrm{PB})$ e energia bruta (EB). As análises químicas foram efetuadas no Laboratório de Nutrição Animal do Departamento de Zootecnia da Universidade Federal de Lavras, segundo a metodologia descrita por Silva \& Queiroz (2002).
Os valores de energia digestível (ED) foram obtidos pela diferença entre a EB dos alimentos e das fezes. Os valores de energia metabolizável (EM) foram obtidos pela diferença entre energia digestível e perdas energéticas, advindas da formação de metano e da urina, para isto se usou a seguinte fórmula, segundo Sniffen et al. (1992). $\mathrm{EM}=\mathrm{EBI}-(\mathrm{EBF}+\mathrm{EBU}+\mathrm{EPGD}), \mathrm{EPGD}=\mathrm{PGD} \mathrm{XEBI} / 100$, $\mathrm{PGD}=4,28+0,059$ CDEB.

A avaliação do consumo voluntário dos nutrientes foi determinada pela diferença entre a quantidade no material fornecido aos animais e a quantidade nas sobras nos cochos. Os valores de digestibilidade aparente (DA) dos nutrientes foram obtidos pela fórmula, conforme metodologia utilizada por Maynard et al. (1984).

$\mathrm{DA}=($ Kgcons $\mathrm{x} \%$ cons $)-(\mathrm{kgsb} \times \% \mathrm{sb})-(\mathrm{kgfz} \times \mathrm{\% fz}) \times 100$, (Kgcons $\mathrm{x} \%$ cons $)-(\mathrm{kgsb} \times \% \mathrm{sb})$

\section{RESULTADOS E DISCUSSÃO}

Os resultados de consumo de matéria seca (CMS), de consumo de matéria orgânica (CMO), fibra em detergente neutro (FD), fibra em detergente ácido (FDA) e o consumo de proteína bruta (CPB) são apresentados Tabela 2.

TABELA 2 - Consumo médio de matéria seca (CMS), matéria orgânica (CMO), fibra em detergente neutro (FD), fibra em detergente ácido (FDA) e proteína bruta (CPB), expressos em g/animal $/$ dia e g/ $/ \mathrm{kg}^{0,75}$ e energia bruta (CEB) em kcal/ani/ dia e $\mathrm{kcal} / \mathrm{kg}^{0,75}$.

\begin{tabular}{lccccc}
\hline \multicolumn{1}{c}{ Variáveis } & $\mathbf{A}$ & $\mathbf{B}$ & $\mathbf{C}$ & $\mathbf{D}$ & CV\% \\
\hline CMS $(\mathrm{g} / \mathrm{ani} / \mathrm{dia})$ & $1198,07 \mathrm{~b}$ & $1380,02 \mathrm{a}$ & $1389,04 \mathrm{a}$ & $1448,04 \mathrm{a}$ & 10,88 \\
$\mathrm{CMS}\left(\mathrm{g} / \mathrm{kg}^{0,75}\right)$ & $65,18 \mathrm{~b}$ & $74,25 \mathrm{a}$ & $78,00 \mathrm{a}$ & $76,66 \mathrm{a}$ & 10,66 \\
$\mathrm{CMO}(\mathrm{g} / \mathrm{ani} / \mathrm{dia})$ & $1146,25 \mathrm{~b}$ & $1318,46 \mathrm{a}$ & $1382,65 \mathrm{a}$ & $1324,70 \mathrm{a}$ & 10,91 \\
$\mathrm{CMO}\left(\mathrm{g} / \mathrm{kg}^{0,75}\right)$ & $62,36 \mathrm{~b}$ & $70,95 \mathrm{a}$ & $73,09 \mathrm{a}$ & $74,48 \mathrm{a}$ & 10,67 \\
$\mathrm{CEB}(\mathrm{kcal} / \mathrm{ani} / \mathrm{dia})$ & $5116,5 \mathrm{~b}$ & $6084,5 \mathrm{a}$ & $6447,2 \mathrm{a}$ & $6062,0 \mathrm{a}$ & 11,40 \\
$\mathrm{CEB}\left(\mathrm{kcal} / \mathrm{kg}^{0,75}\right)$ & $278,17 \mathrm{~b}$ & $327,48 \mathrm{a}$ & $347,45 \mathrm{a}$ & $334,50 \mathrm{a}$ & 11,19 \\
$\mathrm{CPB}(\mathrm{g} / \mathrm{ani} / \mathrm{dia})$ & $232,33 \mathrm{~b}$ & $288,14 \mathrm{a}$ & $316,5 \mathrm{a}$ & $313,05 \mathrm{a}$ & 10,58 \\
$\mathrm{CPB}\left(\mathrm{g} / \mathrm{kg}^{0,75}\right)$ & $12,46 \mathrm{c}$ & $15,53 \mathrm{~b}$ & $17,07 \mathrm{ab}$ & $17,28 \mathrm{a}$ & 10,40 \\
$\mathrm{CFDN}(\mathrm{g} / \mathrm{ani} / \mathrm{dia})$ & $351,03 \mathrm{c}$ & $488,00 \mathrm{~b}$ & $541,17 \mathrm{ab}$ & $604,47 \mathrm{a}$ & 13,63 \\
$\mathrm{CFDN}\left(\mathrm{g} / \mathrm{kg}^{0,75}\right)$ & $19,12 \mathrm{c}$ & $26,34 \mathrm{~b}$ & $29,14 \mathrm{~b}$ & $33,35 \mathrm{a}$ & 13,71 \\
$\mathrm{CFDA}(\mathrm{g} / \mathrm{ani} / \mathrm{dia})$ & $134,77 \mathrm{c}$ & $212,45 \mathrm{~b}$ & $529,74 \mathrm{a}$ & $553,07 \mathrm{a}$ & 7,17 \\
$\mathrm{CFDA}\left(\mathrm{g} / \mathrm{kg}^{0,75}\right)$ & $7,33 \mathrm{c}$ & $11,44 \mathrm{~b}$ & $28,61 \mathrm{a}$ & $30,53 \mathrm{a}$ & 13,92 \\
\hline
\end{tabular}

Médias seguidas pela mesma letra, na mesma linha não diferem pelo teste de Tukey $(\mathrm{P}>0,05)$. 
Era esperado que o consumo de MS, MO, PB e EB nos tratamentos com menores níveis de FDNf (maior proporção de carboidratos estruturais), fossem maiores, contudo este comportamento não foi observado (Tabela 2). O tratamento $\mathrm{A}(8,67 \%$ de FDNf) apresentou o menor consumo de MS, MO e PB.

Ao se realizarem as análises de regressão do CMS, em função dos níveis de FDNf nas dietas, verificou-se que houve efeito dos níveis de FDN total e FDNf, no CMS, CMO, CPB CFDN e CFDA. As equações de regressão encontram-se na Tabelas 3. Estes resultados podem estar associados a alguns fatores, dentre outros: limitação de consumo por alta densidade energética da dieta (alta quantidade de carboidratos solúveis) por um distúrbio nutricional, possivelmente, ocorrência de acidose subclínica. Ao longo do experimento observou-se uma variação no consumo diário dos animais especialmente dos tratamentos A e B, reforçando a idéia de uma acidose subclínica, porém não houve sintomatologia clínica. Neste estudo verificouse efeito quadrático dos níveis de FDN total e FDNf sobre o consumo de matéria seca, energia bruta e proteína bruta (Tabela 3). Neste ponto observa-se a máxima ingestão de MS pelo animal. No presente estudo esse ponto ocorreu com $28,05 \%$ de FDNf na dieta experimental (tendo um consumo de $78,18 \mathrm{~g} / \mathrm{kg}^{0,75}$ ). O consumo máximo de MS foi de $78,00 \mathrm{~g} / \mathrm{kg}^{0,75}$, Silva et al. (2002), trabalhando com ovinos obteve um consumo de $101,97 \mathrm{~g} / \mathrm{kg}^{0,75} \mathrm{com} 40 \%$ de volumoso na dieta. O NRC (1985) cita que, para ovelhas em manutenção, com $50 \mathrm{~kg}$ de peso vivo o consumo de MS deve ser de $1 \mathrm{~kg}$ ou $2,0 \%$ do peso vivo. No presente estudo, o consumo de matéria seca foi de $1007,94 \mathrm{~g} / \mathrm{animal} / \mathrm{dia}$ ou $2,2 \%$ do peso vivo, mostrando que o consumo de matéria seca esteve próximo ao recomendado pelo NRC (1985). O consumo de proteína bruta reduziu com o decréscimo de FDN total e FDNf nas dietas experimentais, possivelmente, influenciados pelos mesmos fatores que afetaram o consumo de matéria seca. Segundo o NRC (1985), o consumo de PB de ovelhas em mantença com $50 \mathrm{~kg}$ de peso vivo é de $95 \mathrm{~g} / \mathrm{dia}$. O maior consumo de PB neste estudo foi de 316,5 g/animal/dia, com $31,71 \%$ de FDNf na dieta.

TABELA 3 - Equações de regressão ajustadas para consumo de matéria seca (CMS), matéria orgânica (CMO), proteína bruta (CPB), fibra em detergente neutro (CFDN) e fibra em detergente ácido (CFDA) expressas em g/animal/dia e g/kg0,75 em função dos níveis de FDN total $(\mathrm{X})$ e FDNf $(\mathrm{X})$ e respectivos coeficientes de variação $(\mathrm{CV})$ nas diferentes dietas.

\begin{tabular}{|c|c|c|c|}
\hline Variáveis & Equações de Regressão FDN Total & $\mathbf{R}^{2}$ & CV \\
\hline CMS (g/ani/dia) & $Y:-2538,6901+202,3522 X-2,5765 X^{2}$ & $96,99 *$ & 10,88 \\
\hline $\operatorname{CMS}\left(\mathrm{g} / \mathrm{k}^{0,75}\right)$ & $\mathrm{Y}:-102,9306+8,9567 \mathrm{X}-0,1110 \mathrm{X}^{2}$ & $97,08 *$ & 10,66 \\
\hline CMO (g/ani/dia) & $Y:-2420,0598+193,3336 X-2,4661 X^{2}$ & $96,95^{*}$ & 10,91 \\
\hline $\mathrm{CMO}\left(\mathrm{g} / \mathrm{k}^{0,75}\right)$ & $Y:-98,3424+8,5746 X-0,1065 X^{2}$ & $97,06 *$ & 10,67 \\
\hline CPB (g/ani/dia) & $Y:-759,3430+52,1425 X-0,6316 X^{2}$ & $96,16 *$ & 10,58 \\
\hline $\mathrm{CPB}\left(\mathrm{g} / \mathrm{k}^{0,75}\right)$ & $\mathrm{Y}:-33,9511+2,4061 \mathrm{X}-0,0282 \mathrm{X}^{2}$ & $96,40 *$ & 10,40 \\
\hline CFDN (g/ani/dia) & Y: $-189,5858+18,7748 X$ & $95,73 *$ & 13,63 \\
\hline CFDN $\left(\mathrm{g} / \mathrm{kg}^{0,75}\right)$ & $\mathrm{Y}:-11,4143+1,0515 \mathrm{X}$ & $97,59 *$ & 13,71 \\
\hline CFDA (g/ani/dia) & $Y:-2,0428+0,0970 X$ & $83,60 *$ & 7,17 \\
\hline CFDA $\left(\mathrm{g} / \mathrm{kg}^{0,75}\right)$ & $Y:-0,8851+0,0975 X$ & $84,25 *$ & 13,92 \\
\hline \multicolumn{4}{|c|}{ Equações de Regressão FDNf } \\
\hline CMS (g/ani/dia) & $Y: 892,7762+42.0727 X-0,7996 X^{2}$ & $99,98 *$ & 10,88 \\
\hline CMS $\left(\mathrm{g} / \mathrm{k}^{0,75}\right)$ & $Y: 50,9654+1,9412 X-0,0346 X^{2}$ & $100,00 *$ & 10,66 \\
\hline CMO (g/ani/dia) & $Y: 855,5143+40,0857 X-0,7651 X^{2}$ & $99,97 *$ & 10,91 \\
\hline $\mathrm{CMO}\left(\mathrm{g} / \mathrm{k}^{0,75}\right)$ & $\mathrm{Y}: 48,8132+1,8516 \mathrm{X}-0,0332 \mathrm{X}^{2}$ & $100,00 *$ & 10,67 \\
\hline CPB (g/ani/dia) & $Y: 145,6084+11,6977 X-0,1979 X^{2}$ & $94,06 *$ & 10,58 \\
\hline CPB $\left(\mathrm{g} / \mathrm{k}^{0,75}\right)$ & $Y: 8,4196+0,5641 X-0,0089 X^{2}$ & $99,99 *$ & 10,40 \\
\hline CFDN (g/ani/dia) & $Y: 200,6975+20,0058 X-0,2451 X^{2}$ & $98,74 *$ & 13,63 \\
\hline $\mathrm{CFDN}\left(\mathrm{g} / \mathrm{k}^{0,75}\right)$ & $\mathrm{Y}: 15,6277+0,5242 \mathrm{X}$ & $96,30 *$ & 13,71 \\
\hline CFDA (g/ani/dia) & $Y: 4,4696+0,0516 X$ & $93,84 *$ & 7,17 \\
\hline CFDA $\left(\mathrm{g} / \mathrm{k}^{0,75}\right)$ & $Y: 1,5554+0,0519 X$ & 94,43 & 13,92 \\
\hline
\end{tabular}

* Significativo a $5 \%$ de probabilidade.

Ciênc. agrotec., Lavras, v. 30, n. 3, p. 547-553, maio/jun., 2006 
O CFDN e CFDA aumentaram, significativamente, com o acréscimo de FDN total e de FDNf na dieta (Tabela 3). O consumo de FDN total, a equação apresentou-se de forma linear. Isso impede concluir que houve uma limitação física do rúmen na regulação do consumo, indicando que este foi, possivelmente, regulado pelo nível energético da dieta (controle fisiológico), porém o consumo de matéria seca esteve um pouco acima do recomendado pelo NRC (1985). No presente estudo, o consumo de FDN foi de $33,35 \mathrm{~g} / \mathrm{PV}^{0,75}$, na dieta com 34,69\% de FDNf, correspondente a $40 \%$ de volumoso, Silva et al. (2002) trabalhando com ovinos, recebendo dietas com diferente níveis de concentrado obteve um consumo de $35,51 \mathrm{~g} / \mathrm{kg}^{0,75}$ na dieta com $40 \%$ de volumoso.O consumo médio de FDN neste estudo foi de 496,16 g, isto representa um consumo de $1,10 \%$ do peso vivo dos animais. A variação no consumo de FDN foi de 0,68 a $1,34 \%$ do peso vivo e o consumo de FDA foi de 0,29 a 1,22\% do peso vivo. A maior variação no consumo de FDA, provavelmente, ocorreu devido à seleção feita pelos animais, que se comportou de forma diferente entre os tratamentos. Nos tratamentos com menor proporção de volumoso houve consumo quase que total e, às vezes, completo do feno, enquanto que nos tratamentos com maior proporção de volumoso, houve consumo parcial do feno, sendo que as sobras continham maior proporção de talos, conseqüentemente maior proporção de FDA, vale lembrar que estas observações foram feitas ao longo do experimento. Os coeficientes da digestibilidade aparente da matéria seca (DMS), matéria orgânica (DMO), energia bruta (DEB), proteína bruta (DPB), fibra em detergente neutro (DFDN), fibra em detergente ácido (DFDA) das diferentes dietas, expressos em porcentagem encontram-se na Tabela 4. As equações de regressão para o DMS e DMO apresentaram-se de forma linear, aumentando de acordo com o decréscimo no nível de FDN total e FDNf das dietas experimentais (Tabela 5).

Segundo Valadares Filho (1985), carboidratos não estruturais possuem coeficiente de digestibilidade aparente total acima de $90 \%$ e carboidratos estruturais próximos de $50 \%$, o que reflete na maior digestão da MS das dietas com menores teores de carboidratos estruturais. No presente estudo observou-se que quando o consumo do MS foi elevado, houve redução na digestibilidade das dietas, provavelmente, em função do aumento de FDNf nas dietas, estes carboidratos apresentam menor digestibilidade, que os carboidratos não estruturais o que, possivelmente, tenha promovido uma queda na digestibilidade das dietas. Contudo, vale lembrar que mesmo as dietas que continham menor quantidade de FDNf (tratamentos A e B) tiveram valores de digestibilidade abaixo do esperado para tais dietas.

No estudo em questão, o DPB não foi influenciado pelos níveis de FDN total das dietas experimentais, provavelmente, devido a uma acidose subclínica, como já mencionado anteriormente, que afetou o consumo de MS, reduzindo-o (Tabela 5). No presente estudo, os tratamentos não influenciaram a DFDN, já a DFDA aumentou linearmente com os níveis de FDN total (Tabela 5). Burger (1998) não registrou influencia dos níveis de concentrado na dieta sobre a DFDN. O fato de no presente estudo não haver diferença significativa dos DFDN, em função dos tratamentos, pode ter relação com a seleção feita pelos animais e com alta quantidade de carboidrato não estrutural presente nas dietas, uma vez que este tipo de carboidrato promove ação depressiva na digestibilidade da fibra (SOEST, 1994). No presente estudo, o aumento nos níveis de FDNf, fez com que as dietas com 26,01 e 34,69\% de FDNf tivessem um DFDA, significativamente, maior do que as dietas com 8,67 e 17,34\% de FDNf.

TABELA 4 - Coeficientes médios de digestibilidade aparente da matéria seca (DMS), matéria orgânica (DMO), energia bruta (DEB), proteína bruta (DPB), fibra em detergente neutro (DFDN), fibra em detergente ácido (DFDA), expressos em porcentagem.

\begin{tabular}{lccccc}
\hline Coeficientes $(\%)$ & A & B & C & D & CV(\%) \\
\hline Digestibilidade da MS & $78,13 \mathrm{a}$ & $74,24 \mathrm{ab}$ & $73,62 \mathrm{~b}$ & $71,95 \mathrm{~b}$ & 5,65 \\
Digestibilidade da MO & $79,34 \mathrm{a}$ & $75,87 \mathrm{ab}$ & $75,14 \mathrm{~b}$ & $73,48 \mathrm{~b}$ & 5,23 \\
Digestibilidade da PB & $74,73 \mathrm{a}$ & $74,95 \mathrm{a}$ & $76,58 \mathrm{a}$ & $77,17 \mathrm{a}$ & 6,38 \\
Digestibilidade da FDN & $57,42 \mathrm{a}$ & $55,78 \mathrm{a}$ & $55,69 \mathrm{a}$ & $59,13 \mathrm{a}$ & 14,80 \\
Digestibilidade da FDA & $49,06 \mathrm{~b}$ & $50,75 \mathrm{~b}$ & $67,68 \mathrm{a}$ & $69,75 \mathrm{a}$ & 12,19 \\
\hline
\end{tabular}

Médias seguidas pela mesma letra, na mesma linha não diferem pelo teste de Tukey $(\mathrm{P}>0,05)$. 
TABELA 5 - Equações de regressão coeficientes da digestibilidade aparente da matéria (DMS), matéria orgânica (DMO), energia bruta (DEB), proteína bruta (DPB), fibra em detergente neutro (DFDN), fibra em detergente ácido (DFDA), expressos em porcentagem, em função dos níveis de FDN total (X) e FDNf (X) das dietas.

\begin{tabular}{lccc}
\hline $\begin{array}{c}\text { Coeficientes } \\
(\boldsymbol{\%})\end{array}$ & Equações de Regressão FDN total & $\begin{array}{c}\text { CV } \\
(\boldsymbol{\%})\end{array}$ & $\begin{array}{c}\mathbf{R}^{\mathbf{2}} \\
(\boldsymbol{\%})\end{array}$ \\
\hline Digestibilidade da MS & Y: $0,9097-0,0045 \mathrm{X}$ & 5,65 & $94,23^{*}$ \\
Digestibilidade da MO & Y: $0,9167-0,0043 \mathrm{X}$ & 5,23 & $95,95^{*}$ \\
Digestibilidade da PB & Y: NS & 6,38 & \\
Digestibilidade da FDN & Y: NS & 14,80 & \\
Digestibilidade da FDA & Y: -0,0026+0,0162X & 22,19 & $71,02^{*}$ \\
\hline Digestibilidade da MS & Equações de Regressão FDNf & & \\
\hline Digestibilidade da MO & Y: 0,7925-0,0022X & 5,65 & $89,00^{*}$ \\
Digestibilidade da PB & Y: $0,8054-0,0021 X$ & 5,23 & $91,86^{*}$ \\
Digestibilidade da FDN & Y: NS & 6,38 & \\
Digestibilidade da FDA & Y: NS & 14,80 & \\
\hline
\end{tabular}

NS - Não-significativo * Significativo a $5 \%$ de probabilidade.

\section{CONCLUSÕES}

Os consumos de FDN e FDA apresentaram-se de forma linear, aumentando de acordo com o acréscimo de FDN total e FDNf na dieta. Os consumos de MS, MO, EB, ED, EM, PB e PD foram afetados pelos tratamentos

Ficou evidenciado que o consumo dos animais foi regulado pela alta densidade energética da dieta (regulação fisiológica), pois as quantidades FDNf não foram suficientes para promover um enchimento ruminal (regulação física). A digestibilidade aparente de MS, MO e FDA aumentarou com a diminuição nos níveis de FDN total e FDNf das dietas. A digestibilidade aparente da PB e FDN não foram afetadas pelos níveis de FDN total e FDNf das dietas.

Com este trabalho evidenciou-se que existe um limite fisiológico para utilização de concentrado na dieta de ovinos, sendo necessário um mínimo de FDN total e FDNf para maior eficiência no aproveitamento dos nutrientes.

\section{REFERÊNCIAS BIBLIOGRÁFICAS}

AGRICULTURAL RESEARCH COUNCIL. The nutrient requirement of farm animals. London, 1980.351 p.
BURGER, P. J. Consumo, digestibilidade, eficiência microbiana, cinética da digestão e comportamento ingestivo em bezerros holandeses. 1998. $113 \mathrm{f}$. Tese (Doutorado em Zootecnia) - Universidade Federal de Viçosa, Viçosa, 1998.

GRANT, R. J.; MERTENS, D. R. Development of buffer systen for $\mathrm{pH}$ control and evaluation of ph effects on fiber digestion in vitro. Journal Dairy Science, Champaign, v. 75, p. 1581-1587, 1992.

MAYNARD, L. A. et al. Nutrição animal. 3. ed. Rio de Janeiro: F. Bastos, 1984. 726 p.

MERTENS, D. R. Análise da fibra e sua utilização na avaliação de alimentos e formulação de rações. In: SIMPÓSIO INTERNACIONAL DE RUMINANTES, 1992, Lavras. Anais... Lavras: SBZ-ESAL, 1992. p. 188.

NATIONAL RESEARCH COUNCIL. Nutrient requirement of sheep. 6. ed. Washington: National Academy, 1985. 99 p.

RODE, L. M.; WEAKLEY, D. C.; SATTER, L. D. Effect of forage amount and particle size in diets of lactating dairy cows on site digestion and microbial protein synthesis. Canadian Journal Animal Science, Ottawa, v. 65, p. 101-111, 1985. 
SANTINI, F. J. et al. Dietary fiber and milk yield, mastication, digestión, and rate of pasaje in gotas fed alfafa hay. Journal Dairy Science, Champaign, v. 75, p. 209-219, 1992.

SAS INSTITUTE. User's guide: statistical analysis systems. Cary, 1992.

SILVA, A. M. A.; SILVA SOBRINHO, A. G.; TRINDADE, I. A. C. M.; RESENDE, K. T. VIEIRA, E. L. Efeito de diferentes níveis de fibra detergente neutro na ingestão de nutrientes em cordeiros lanados e deslanados. In: REUNIÃO ANUAL DA SOCIEDADE BRASILEIRA DE ZOOTECNIA, 39., 2002, Recife. Anais... Recife: SBZ, 2002.
SILVA, D. J.; QUEIROZ, A. C. Análise de alimentos: métodos químicos e biológicos. 3. ed. Viçosa: UFV, 2002.

SNIFFEN, C. J. et al. A net carbohydrate and protein availability. Journal Animal Science, Champaign, v. 70, n. 3, p. 3562-3577, 1992.

SOEST, P. J. van. Nutritional ecology of the ruminat. 2. ed. Ithaca: Cornell University, 1994. 476 p.

VALADARES FILHO, S. C. Digestão total e parcial da matéria seca e carboidratos em bovinos e bubalinos. 1985 . $148 \mathrm{f}$. Tese (Doutorado em Zootecnia) - Universidade Federal de Viçosa, Viçosa, 1985. 